\title{
EFFECTS OF MATCH LOCATION, QUALITY OF OPPOSITION, MATCH OUTCOME, AND PLAYING POSITION ON LOAD PARAMETERS AND PLAYERS' PROMINENCE DURING OFFICIAL MATCHES IN PROFESSIONAL SOCCER PLAYERS
}

original paper

(1) University School of Physical Education in Wroclaw

DOI: https://doi.org/10.5114/hm.2021.100322

\author{
LUIZ GUILHERME CRUZ GONÇALVES ${ }^{1}$, FILIPE MANUEL CLEMENTE ${ }^{2,3}$, \\ LUIZ HENRIQUE PALUCCI VIEIRA ${ }^{4}$, BRUNO BEDO ${ }^{5}$, ENRICO FUINI PUGGINA ${ }^{5}$, \\ FELIPE MOURA $^{6}$, FILIPE MESQUITA ${ }^{5}$, PAULO ROBERTO PEREIRA SANTIAGO ${ }^{5}$, \\ RODRIGO ALMEIDA ${ }^{7}$, RODRIGO AQUINO ${ }^{7}$ \\ ${ }^{1}$ Botafogo Football Club S/A, Ribeirão Preto, Brazil \\ ${ }^{2}$ School of Sport and Leisure, Polytechnic Institute of Viana do Castelo, Melgaço, Portugal \\ ${ }^{3}$ Instituto de Telecomunicações, Delegação da Covilhã, Covilhã, Portugal \\ ${ }^{4}$ Human Movement Research Laboratory, São Paulo State University, Bauru, Brazil \\ ${ }^{5}$ University of São Paulo, São Paulo, Brazil \\ ${ }^{6}$ Laboratory of Applied Biomechanics, Sports Sciences Department, State University of Londrina, Londrina, Brazil \\ ${ }^{7}$ Federal University of Espírito Santo, Goiabeiras, Vitória, Brazil
}

\begin{abstract}
Purpose. This study aimed to investigate the effects of match location, quality of opposition, match outcome, and playing position on internal load (IL), external load (EL), and interpersonal interactions in professional soccer players. Also, the relationships between load parameters and interpersonal interactions were measured.

Methods. Fourteen matches from 16 Brazilian professional players were analysed. IL was obtained through the rating of perceived exertion. EL was quantified with the Global Positioning System (e.g., high-intensity running [HIR]). Interpersonal interactions were measured by network analysis using completed passes between teammates $(n=2845)$.

Results. Higher values of match IL and HIR were observed in home vs. away matches $(p=0.02)$. Players presented greater running outputs and number of networks that a player controlled in matches against strong vs. weak opponents $(p<0.05)$. When the players won the matches, higher running demands and proximity to the teammates (i.e., closeness centrality) were demonstrated than when they drew or lost $(p<0.05)$. Reduced values of IL, EL, and closeness centrality were observed in the forwards compared with the other positions $(p<0.05)$. The distance covered per minute in HIR was large and associated with closeness centrality and eigenvector $(r=0.55 ; p<0.001)$.
\end{abstract}

Conclusions. The results indicate that load parameters and interpersonal interactions are influenced by the considered independent variables.

Key words: association football, match load, match analysis, time-motion analysis, sports sciences

\section{Introduction}

Match analysis in team sports is an important tool to increase knowledge of players and collective performance, especially to report the real-practice demands during official conditions, which provide insights for coaches to plan more specific training sessions [1]. The ability of given players to coordinate their actions with those of others (i.e., teammates and opponents) is often paramount for succeeding in soccer performance contexts [2]. Recent research recommends social network analysis to verify interpersonal interactions using completed passes between teammates [3-5]. Furthermore, a holistic approach, applying social network analysis and physical performance, could provide a comprehensive match analysis to assist match understanding

Correspondence address: Rodrigo Aquino, Center of Physical Education and Sport, Federal University of Espírito Santo, Av. Fernando Ferrari 514, Goiabeiras, Vitória, ES, Postal Code 29075-910, Brazil, e-mail: aquino.rlq@gmail.com

Received: May 7, 2020

Accepted for publication: August 6, 2020

Citation: Gonçalves LGC, Clemente FM, Vieira LHP, Bedo B, Puggina EF, Moura F, Mesquita F, Santiago PRP, Almeida R, Aquino R. Effects of match location, quality of opposition, match outcome, and playing position on load parameters and players' prominence during official matches in professional soccer players. Hum Mov. 2021;22(3):35-44; doi: https://doi.org/10.5114/ hm.2021.100322. 
and decision-making with regard to training content and prescriptions. During soccer matches, performance emerges from the task (e.g., contextual variables), environment (e.g., temperature), and individual constraints (e.g., positional role). For example, in matches played at home, against weaker opponents, and resulted in win, players demonstrated greater running outputs (external load [EL]) and individual/global metrics of network analysis compared with their counterparts [6]. Also, reduced values of running performance variables were reported in central defenders and forwards compared with other positions [7]. Midfielders presented greater proximity to their teammates and controlled a greater number of networks during the offensive phases when compared with defenders and forwards [6].

An additional perceptual-physical performance variable identified in soccer is the ability to accurately control and monitor internal load (IL), for example through ratings of perceived exertion (RPE) during soccer training routines [8]. A recent meta-analysis showed large correlations between session-RPE (sRPE) training load and total distance covered (TD) during official matches in team sports $(r=0.82 ; 90 \%$ confidence interval: 0.75-0.87) [9]. However, the utility of the RPEmethod to analyse the real match-play physical demands in competitive matches still requires better understanding [10]. Official soccer matches provide a favourable condition to observe practical validity, assessing the possible relationships between RPE and EL [11]. Weston et al. [12] showed small associations $(r$ : 0.14-0.28) between match-RPE and EL variables derived from Global Positioning Systems (GPS) during Australian football matches. However, the effects of contextual variables on RPE measurements were not fully reported.

A previous work verified a non-significant association between physical (e.g., high-speed running) and skill-related (e.g., successful passes percentage) performance in professional soccer match play [13]. In contrast, other studies reported large associations between emergent metrics of social network analysis (e.g., how close the player is to the teammates - closeness centrality) and high-intensity running during matches $[6,14]$. In addition, Aquino et al. [6] showed that midfielders presented greater closeness centrality compared with the other positions. Therefore, understanding these relationships can aid sports science and coaching practitioners to prescribe position-specific training and to manage each athlete along the season, considering the possible influence of situational variables (i.e., match location, quality of opposition) and match outcome. For example, midfielders should be physically prepared to respond to greater running demands during matches to play a crucial role in the offensive and defensive phase. Moreover, when players compete at home against strong opponents, it is possible that coaches and practitioners could adopt pacing strategies during the training sessions to support great interpersonal cooperative/ competitive interactions and match physical requirements. Therefore, the aims of this study were: (i) to investigate the effects of match location, quality of opposition, match outcome, and playing position on load parameters (i.e., IL, EL) and players' prominence (i.e., individual metrics of social network analysis) in professional soccer players during official matches; and (ii) to verify the relationships between load parameters and players' prominence.

\section{Material and methods}

\section{Participants}

Data were collected from 16 elite-level players (mean [standard deviation]: age: 26.3 [4.1] years; body mass: 77.3 [8.0] kg; height: 180.0 [0.1] cm) during the 2018 $1^{\text {st }}$ São Paulo State Championship (from January 18 to May 22). The players were assessed during 14 matches, with a total of 86 individual player observations. Match files were classified in accordance with playing position - external defenders ( $n=24$ observations), central defenders ( $n=19$ observations), external midfielders ( $n=15$ observations), central midfielders ( $n=17$ observations), and forwards ( $n=11$ observations). We included GPS data only for the players who participated for $\geq 90 \mathrm{~min}$ in each match, with the goalkeeper as an exception. Moreover, during the competition, some GPS units presented measurement problems (i.e., high error rate and low intraclass correlation coefficients), probably because of the environmental characteristics in the stadium, among other factors (for more information, see Palucci Vieira et al. [15]). In relation to field players' prominence analysis (i.e., social network), 14 adjacency matrices (14 matches) were built considering all the players ( $n=11$, including the goalkeeper). If a player was replaced, the substitute was included in the adjacency matrix at the same original place. However, the individual metrics of social network analysis of these 2 players (substitute and player replaced) and the goalkeepers were not included in the data analysis (playing time $<90 \mathrm{~min}$ ). Thus, the centrality measures of the other players were not impacted. The reference team analysed typically played in 1-4-3-3 and 1-44-2 formations (reported by the coaching staff), with minimal variations. 


\section{Design}

The players were observed during 14 soccer matches in the $20181^{\text {st }}$ São Paulo State Championship, the leading state-level tournament in the country [16]. This tournament was composed of 5 groups of 4 teams, totalling 20 teams. In the present study, the possible influence of contextual variables (match location [playing at home or away]; quality of opposition [weak, intermediary, or strong]), match outcome (lost, draw, or won), and playing position (external defender; central defender; external midfielder; central midfielder; forward) was observed on match running performance (EL), IL, and players' prominence (social network analysis). Specifically, EL was assessed by using measurements derived from GPS. IL was quantified with $\mathrm{RPE} *$ total minutes of the match (considering the amount of extra-time). Players' prominences were quantified through social network analysis by counting the completed passes between teammates. Incomplete passes were not counted. The matches $(2 \times 45$ minutes $)$ were performed in official stadiums (FIFA recommendations: natural grass, ca. $105 \times 68 \mathrm{~m}$ ), between 4:00 pm and 10:00 pm.

\section{Measures}

\section{Internal load}

The players were familiarized with the use of the centiMax scale (CR100) for the RPE method [17]. A previous study demonstrated the construct validity, reliability, application, and sensitivity with soccer players [18]. Thirty minutes after the matches, the following question was asked to the players: 'How was your workout?' Two indices were registered: (i) match-reported RPE (sRPE); and (ii) match load (minutes played * RPE [sRPE-ML]). The CR100 scores were provided individually, and hearing the teammates' answers was prevented.

\section{External load}

Match running performance was recorded with a portable GPS (QSTARZ, $5 \mathrm{~Hz}$, Taipei, Taiwan). All devices were activated 15 minutes before the data collection to allow acquisition of satellite signal [19]. The players used the same unit throughout the championship [20]. After the matches, data were downloaded by using the same version of the appropriate software (Qstarz International Co., GPS View, version 1.2.24) and exported to a CSV format for further analysis in the MATLAB ${ }^{\circledast}$ environment (MathWorks Inc., Natick, USA). With specific scripts, the geographic coordinates were converted to Cartesian coordinates $(x, y)$ and smoothed by a Butterworth digital filter (third order; cut-off frequency: $0.4 \mathrm{~Hz}$ ) for posterior calculation of TD and the arbitrary speed thresholds. The individual thresholds were based on the individual's maximum running speed during the matches; low-intensity running (LIR) covered $0-59.99 \%$, and high-intensity running (HIR) covered 60-100\%. All running measures were relativized per minutes played. We selected Butterworth third order filter with $0.4-\mathrm{Hz}$ cut-off frequency to smooth positional data in accordance with a control-quality assessment of the GPS units in a pilot study and previous research [6]. The players wearing a GPS device covered a known distance (calculated with a tape measure) at different speed zones $\left(12 \mathrm{~km} \cdot \mathrm{h}^{-1}, 18 \mathrm{~km} \cdot \mathrm{h}^{-1}, 24 \mathrm{~km} \cdot \mathrm{h}^{-1}\right)$. The error rate was $<5 \%$. Moreover, the validity (standard error of estimate: $1.3-6.8 \%$ ) and reliability (coefficient of variation: $2.03-7.71 \%$ ) of the method had been previously established [21].

\section{Players' prominence}

A previous study demonstrated that completed passes between teammates could be considered the most consequential form of interpersonal interaction in soccer matches [4]. In the present study, 14 matches were recorded (Casio EX-FH25; $30 \mathrm{~Hz} ; 720 \times 480$ pixels) and 2845 passes were manually registered for further analysis. Five matches (1052 passes; 37\% of the total) were reanalysed by 2 observers (LGCG and RA) for inter- and intra-rater reliability analysis. Intraclass correlation coefficients equalled 0.94 (interrater) and 0.97 (intra-rater). One global adjacency matrix (i.e., using a simple spreadsheet table) was elaborated for each match. The matrices were used to build a finite $n \times n$ network, where entries coded by number 1 , for instance, represented ways that players interacted [5]. The Gephi (0.9.2) software served to calculate the importance of a vertex (i.e., player) in a graph through 4 measures (for more details, see Ribeiro et al. [5], Borgatti [22], Freeman [23], Gudmundsson and Horton [24]): (i) in- and out-degree (i.e., the number of completed passes that a player received and performed, respectively); (ii) closeness centrality of a vertex, defined as the sum of distances from all other vertices presented in a graph (i.e., which represents how close the player was to the teammates); (iii) betweenness centrality, defined as the number of times that a vertex connected 2 other vertices through their shortest paths 


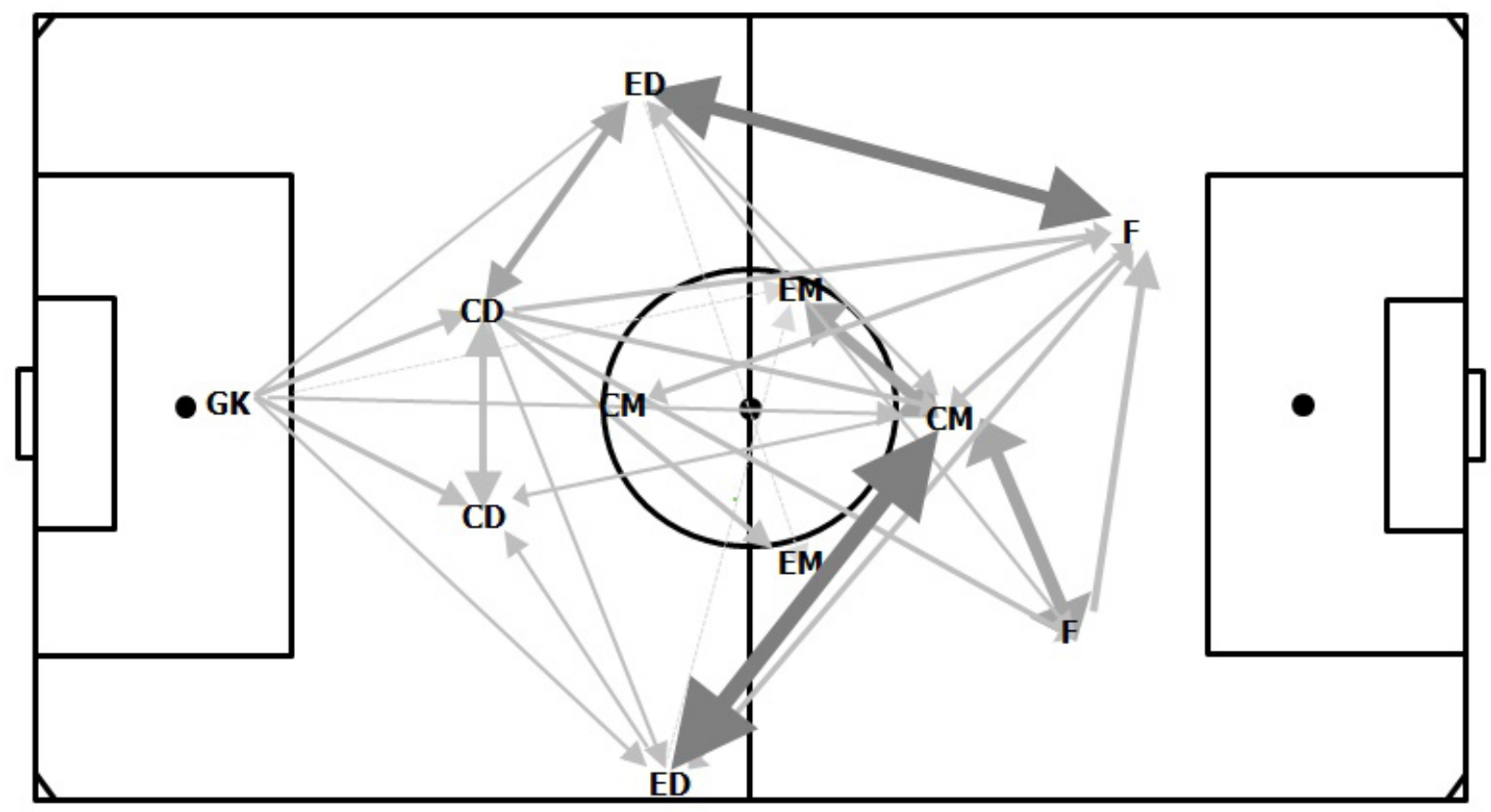

GK - goalkeeper, CD - central defender, ED - external defender, CM - central midfielder, EM - external midfielder, F - forward

Figure 1. Draw-representation of team interactions using completed passes between teammates during an official match. Team displayed in a 1-4-4-2 formation. Adjacency matrix was processed with Gephi 0.9.2. Grey arrows represent pass directions. The width and colour intensity of each arrow represents the quantity of passes completed between players during performance [5]

(i.e., the number of networks that a player controlled; player that connected the midfield and attack areas); and (iv) eigenvector, which measures the influence of a vertex in a graph (i.e., identifies key players who played a crucial role in the offensive phases). Figure 1 demonstrates a draw-representation of the match interactions between teammates.

\section{Situational variables and match outcome}

The $20181^{\text {st }}$ São Paulo State Championship involved 16 teams. The reference team played 12 matches at the group stage and 2 matches in playoffs (i.e., quarterfinals). Their end-ranking was $8 / 16$. Therefore, the reference team played 14 matches ( 7 home [ 41 observations], 7 away [ 41 observations]; 2 against strong [13 observations], 8 against intermediary [49 observations], 4 against weak opponents [24 observations]; 4 losses [25 observations], 6 draws [36 observations], 4 wins [25 observations]; 9 goals scored, 11 conceded). During the 7 away matches, the players travelled a total of $2.050 \mathrm{~km}$ (average of $293 \mathrm{~km}$ per match). The quality of opposition was calculated in accordance with K-mean cluster analysis on the basis of the cumulative sum of points per match (end-league ranking of actual season) [16]. Three clusters were identified: best ranking (strong opponents [1-2 team ranking]), intermediary ranking (intermediary opponents [3-11 team ranking]), and worst ranking (weak opponents [12-16 team ranking]).

\section{Statistical analysis}

Statistical analysis was performed with the IBM SPSS Statistics software for Windows, version 22.0 (IBM Corp.), unless otherwise stated. Data normality was checked with the Kolmogorov-Smirnov test. Descriptive statistics are presented as mean (standard deviation). Match location was compared by using the $t$-test for independent samples. Quality of opposition, match outcome, and playing position were compared with the use of the univariate general linear model for independent samples. Interaction effects were also verified. When necessary, nonparametric counterpart tests and the Bonferroni post-hoc were applied. The relationships between load parameters and players' prominence were measured with the Pearson's correlation coefficient. The magnitudes of correlation coefficients were considered trivial $(r<0.1)$, small $(0.1<r<0.3)$, moderate $(0.3<r<0.5)$, large $(0.5<r<0.7)$, very large $(0.7<r<0.9)$, and nearly perfect $(r=1.0)$, in accordance with a study by Hopkins [25]. The statistical significance of the results was accepted at $p<0.05$. 
Furthermore, a magnitude-based inference was used. Previous editorials pointing out those philosophical goals of sport and exercise science are better served using estimation approach and statistical methods that embody this, e.g., magnitude-based inferences and decisions (e.g., Wilkinson and Winter [26], de Koning and Noordhof [27]). With specific Microsoft Excel spreadsheets (www.sportsci.org/), with a $90 \%$ confidence interval, the quantitative chance of higher or lower differences referring to the effect size $(E S)$ was assessed qualitatively as follows: $<1 \%$, almost certainly not; $1-5 \%$, very unlikely; $5-25 \%$, unlikely; $25-75 \%$, possible; 75-95\%, likely; 95-99\%, very likely; > 99\%, almost certain. If the chance of higher or lower differences was $>5 \%$, the true difference was assumed as unclear [28]. For the greater impact of the results in the field, only likely chances that the differences were true (> 75\%) were considered, as in a previous study [29].

\section{Ethical approval}

The research related to human use has complied with all the relevant national regulations and institutional policies, has followed the tenets of the Declaration of Helsinki, and has been approved by the local university ethical committee (School of Physical Education and Sport, Ribeirão Preto, São Paulo, Brazil; protocol number: 61884716.9.0000.5659).

\section{Informed consent}

Informed consent has been obtained from all individuals included in this study.

\section{Results}

Table 1 shows the effects of match location, quality of opposition, and match outcome on IL, EL, and players' prominence. The players perceived higher match load (sRPE-ML) and covered more HIR per minute in home vs. away matches ( $p=0.02$; ES: 0.32-0.37; likely). Matches against strong opponents resulted in greater $\mathrm{TD}$ and lower betweenness centrality than those against weak opponents ( $p<0.05$; ES: 0.40-0.71; likely-very likely). When the players won, higher values of TD, LIR, HIR, and closeness centrality were observed compared with a draw ( $p$ : 0.02-0.04; ES: 0.35-0.58; likely) and loss ( $p$ : 0.02-0.04; ES: 0.35-0.53; likely). Interaction effects of match location, quality of opposition, or match outcome on running performance and metrics of social

Table 1. Effects of match location, quality of opposition, and match outcome on load parameters and metrics of social network analysis: mean (standard deviation)

\begin{tabular}{|c|c|c|c|c|c|c|c|c|}
\hline \multirow{2}{*}{ Variables } & \multicolumn{2}{|c|}{ Match location } & \multicolumn{3}{|c|}{ Quality of opposition } & \multicolumn{3}{|c|}{ Match outcome } \\
\hline & Away & Home & Weak & Intermediary & Strong & Lost & Draw & Won \\
\hline \multicolumn{9}{|l|}{ Internal load } \\
\hline sRPE (AU) & $\begin{array}{c}81.8 \\
(13.0)\end{array}$ & $\begin{array}{c}83.9 \\
(11.4)\end{array}$ & $\begin{array}{c}81.5 \\
(15.0)\end{array}$ & $\begin{array}{c}83.6 \\
(11.3)\end{array}$ & $\begin{array}{c}82.2 \\
(10.7)\end{array}$ & $\begin{array}{c}80.9 \\
(12.4)\end{array}$ & $\begin{array}{c}84.6 \\
(13.3)\end{array}$ & $\begin{array}{c}82.1 \\
(10.7)\end{array}$ \\
\hline sRPE-ML (AU) & $\begin{array}{c}7662.7 \\
(1335.1)\end{array}$ & $\begin{array}{l}7963.4^{*, a} \\
(1132.9)\end{array}$ & $\begin{array}{c}7665.0 \\
(1516.3)\end{array}$ & $\begin{array}{c}7891.0 \\
(1132.5)\end{array}$ & $\begin{array}{c}7746.5 \\
(1168.5)\end{array}$ & $\begin{array}{c}7583.4 \\
(1221.0)\end{array}$ & $\begin{array}{c}8000.8 \\
(1336.1)\end{array}$ & $\begin{array}{c}7748.4 \\
(1132.2)\end{array}$ \\
\hline \multicolumn{9}{|l|}{ External load } \\
\hline $\mathrm{TD}\left(\mathrm{m} \cdot \mathrm{min}^{-1}\right)$ & $\begin{array}{c}88.2 \\
(10.3)\end{array}$ & $\begin{array}{c}90.5 \\
(12.5)\end{array}$ & $\begin{array}{c}88.5 \\
(19.4)\end{array}$ & $\begin{array}{l}87.7 \\
(9.2)\end{array}$ & $\begin{array}{c}93.0^{* *, b} \\
(9.3)\end{array}$ & $\begin{array}{c}85.7 \\
(15.0)\end{array}$ & $\begin{array}{l}89.2 \\
(9.3)\end{array}$ & $\begin{array}{c}93.0^{*, \mathrm{~d}} \\
(8.9)\end{array}$ \\
\hline $\operatorname{LIR}\left(\mathrm{m} \cdot \min ^{-1}\right)$ & $\begin{array}{l}79.7 \\
(9.2)\end{array}$ & $\begin{array}{l}82.2 \\
(7.2)\end{array}$ & $\begin{array}{l}82.3 \\
(9.6)\end{array}$ & $\begin{array}{l}79.1 \\
(7.7)\end{array}$ & $\begin{array}{l}83.7 \\
(8.3)\end{array}$ & $\begin{array}{l}78.6 \\
(9.3)\end{array}$ & $\begin{array}{l}80.5 \\
(7.6)\end{array}$ & $\begin{array}{c}83.7^{*, \mathrm{~d}} \\
(7.9)\end{array}$ \\
\hline $\operatorname{HIR}\left(\mathrm{m} \cdot \mathrm{min}^{-1}\right)$ & $\begin{array}{c}8.4 \\
(2.4)\end{array}$ & $\begin{array}{l}9.3^{*, \mathrm{a}} \\
(3.1)\end{array}$ & $\begin{array}{c}9.2 \\
(4.1)\end{array}$ & $\begin{array}{c}8.6 \\
(2.6)\end{array}$ & $\begin{array}{c}9.2 \\
(2.4)\end{array}$ & $\begin{array}{c}8.6 \\
(3.5)\end{array}$ & $\begin{array}{c}8.7 \\
(2.5)\end{array}$ & $\begin{array}{l}9.4^{*, \mathrm{~d}} \\
(2.4)\end{array}$ \\
\hline \multicolumn{9}{|l|}{ Metrics } \\
\hline In-degree & $30.7(10.1)$ & $30.3(12.2)$ & $28.4(11.6)$ & $32.2(10.7)$ & $33.5(9.7)$ & $31.0(10.8)$ & $30.2(8.6)$ & $30.4(13.7)$ \\
\hline Out-degree & $28.3(11.0)$ & $28.4(12.8)$ & $26.3(11.5)$ & $29.5(12.1)$ & $32.1(12.1)$ & $29.5(11.2)$ & $27.2(12.2)$ & $28.4(12.4)$ \\
\hline Closeness centrality & $0.8(0.1)$ & $0.8(0.1)$ & $0.8(0.1)$ & $0.8(0.1)$ & $0.8(0.1)$ & $0.7(0.1)$ & $0.7(0.1)$ & $0.8(0.1)^{*, d}$ \\
\hline Betweenness centrality & $6.4(3.7)$ & $5.2(3.2)$ & $6.7(3.7)$ & $5.3(3.4)$ & $3.9(2.1)^{*, \mathrm{c}}$ & $5.0(2.5)$ & $5.5(4.1)$ & $6.9(3.6)$ \\
\hline Eigenvector & $0.8(0.1)$ & $0.8(0.1)$ & $0.8(0.1)$ & $0.8(0.1)$ & $0.8(0.1)$ & $0.8(0.1)$ & $0.8(0.1)$ & $0.8(0.1)$ \\
\hline
\end{tabular}

sRPE - session rate of perceived exertion, AU - arbitrary units, sRPE-ML - session rate of perceived exertion - match load, TD - total distance covered, LIR - low-intensity running, HIR - high-intensity running

${ }^{\mathrm{a}}$ home $>$ away, ${ }^{\mathrm{b}}$ strong $>$ weak, ${ }^{\mathrm{c}}$ strong < weak, ${ }^{\mathrm{d}}$ won $>$ draw/lost, * 75-95\%, likely and $p<0.05, * * 95-99 \%$, very likely and $p<0.01$ 


\section{HUMAN MOVEMENT}

L. Gonçalves et al., Match analysis in soccer

Table 2. Comparisons of load parameters and metrics of social network analysis depending on playing position: mean (standard deviation)

\begin{tabular}{|c|c|c|c|c|c|c|}
\hline Variables & $\begin{array}{l}\text { External } \\
\text { defender } \\
\text { (ED) }\end{array}$ & $\begin{array}{l}\text { Central } \\
\text { defender } \\
\text { (CD) }\end{array}$ & $\begin{array}{l}\text { Central } \\
\text { midfielder } \\
(\mathrm{CM})\end{array}$ & $\begin{array}{l}\text { External } \\
\text { midfielder } \\
(\mathrm{EM})\end{array}$ & $\begin{array}{l}\text { Forward } \\
\text { (F) }\end{array}$ & Differences \\
\hline \multicolumn{7}{|l|}{ Internal load } \\
\hline sRPE (AU) & $86.7(6.8)$ & $77.6(17.1)$ & $85.4(9.1)$ & $87.0(8.8)$ & $74.3(13.6)$ & $\begin{array}{c}* * * \mathrm{~F}<\mathrm{ED} / \mathrm{CD} / \mathrm{EM} / \mathrm{CM} \\
{ }^{* *} \mathrm{CD}<\mathrm{ED} / \mathrm{EM} / \mathrm{CM} \\
* *{ }^{*} \mathrm{ED} / \mathrm{EM}>\mathrm{CD} / \mathrm{CM}\end{array}$ \\
\hline sRPE-ML (AU) & $\begin{array}{l}8130.0 \\
(925.5)\end{array}$ & $\begin{array}{c}7402.8 \\
(1644.5)\end{array}$ & $\begin{array}{l}8093.9 \\
(837.9)\end{array}$ & $\begin{array}{c}8126.0 \\
(1046.2)\end{array}$ & $\begin{array}{c}6938.0 \\
(1454.9)\end{array}$ & $\begin{array}{c}* * * \mathrm{~F}<\mathrm{ED} / \mathrm{CD} / \mathrm{EM} / \mathrm{CM} \\
{ }^{* *} \mathrm{CD}<\mathrm{ED} / \mathrm{EM} / \mathrm{CM} \\
* * * \mathrm{ED} / \mathrm{EM}>\mathrm{CD} / \mathrm{CM}\end{array}$ \\
\hline \multicolumn{7}{|l|}{ External load } \\
\hline $\mathrm{TD}\left(\mathrm{m} \cdot \mathrm{min}^{-1}\right)$ & $95.0(8.7)$ & $85.8(5.6)$ & $92.2(11.4)$ & $86.9(9.2)$ & $81.7(18.9)$ & $* * * \mathrm{~F}<\mathrm{ED} / \mathrm{CD} / \mathrm{EM} / \mathrm{CM}$ \\
\hline $\operatorname{LIR}\left(\mathrm{m} \cdot \min ^{-1}\right)$ & $84.9(7.9)$ & $80.4(5.3)$ & $83.5(9.1)$ & $79.4(7.1)$ & $77.5(9.8)$ & $* * * \mathrm{~F}<\mathrm{ED} / \mathrm{CD} / \mathrm{EM} / \mathrm{CM}$ \\
\hline $\operatorname{HIR}\left(\mathrm{m} \cdot \mathrm{min}^{-1}\right)$ & $10.1(2.5)$ & $8.3(1.9)$ & $8.7(3.7)$ & $8.7(3.1)$ & $7.8(2.4)$ & ${ }^{* * *} \mathrm{~F}<\mathrm{ED} / \mathrm{CD} / \mathrm{EM} / \mathrm{CM}$ \\
\hline \multicolumn{7}{|l|}{ Metrics } \\
\hline In-degree & $33.4(8.2)$ & $24.4(10.8)$ & $33.9(11.5)$ & $36.7(12.1)$ & $22.5(5.7)$ & ${ }^{*} \mathrm{ED} / \mathrm{CM} / \mathrm{EM}>\mathrm{CD} / \mathrm{F}$ \\
\hline Out-degree & $29.0(9.3)$ & $27.7(10)$ & $37.7(11.5)$ & $30.2(9.4)$ & $12.0(4.1)$ & ${ }^{*} \mathrm{ED} / \mathrm{CM} / \mathrm{EM}>\mathrm{CD} / \mathrm{F}$ \\
\hline Closeness centralit & $0.8(0.1)$ & $0.8(0.1)$ & $0.8(0.1)$ & $0.8(0.1)$ & $0.7(0.1)$ & ${ }^{*} \mathrm{~F}<\mathrm{ED} / \mathrm{CD} / \mathrm{EM} / \mathrm{CM}$ \\
\hline Betweenness centrality & $5.6(3.7)$ & $5.2(2.6)$ & $7.1(3.0)$ & $6.3(4.4)$ & $4.6(3.8)$ & - \\
\hline Eigenvector & $0.8(0.1)$ & $0.7(0.1)$ & $0.9(0.1)$ & $0.9(0.1)$ & $0.8(0.1)$ & ${ }^{*} \mathrm{CM} / \mathrm{EM}>\mathrm{ED} / \mathrm{F}>\mathrm{CD}$ \\
\hline
\end{tabular}

sRPE - session rate of perceived exertion, AU - arbitrary units, sRPE-ML - session rate of perceived exertion - match load, TD - total distance covered, LIR - low-intensity running, HIR - high-intensity running

${ }^{*} 75-95 \%$, likely and $p<0.05,{ }^{* *} 95-99 \%$, very likely and $p<0.01,{ }^{* * *}>99 \%$, almost certain and $p<0.001,-$ no statistical difference
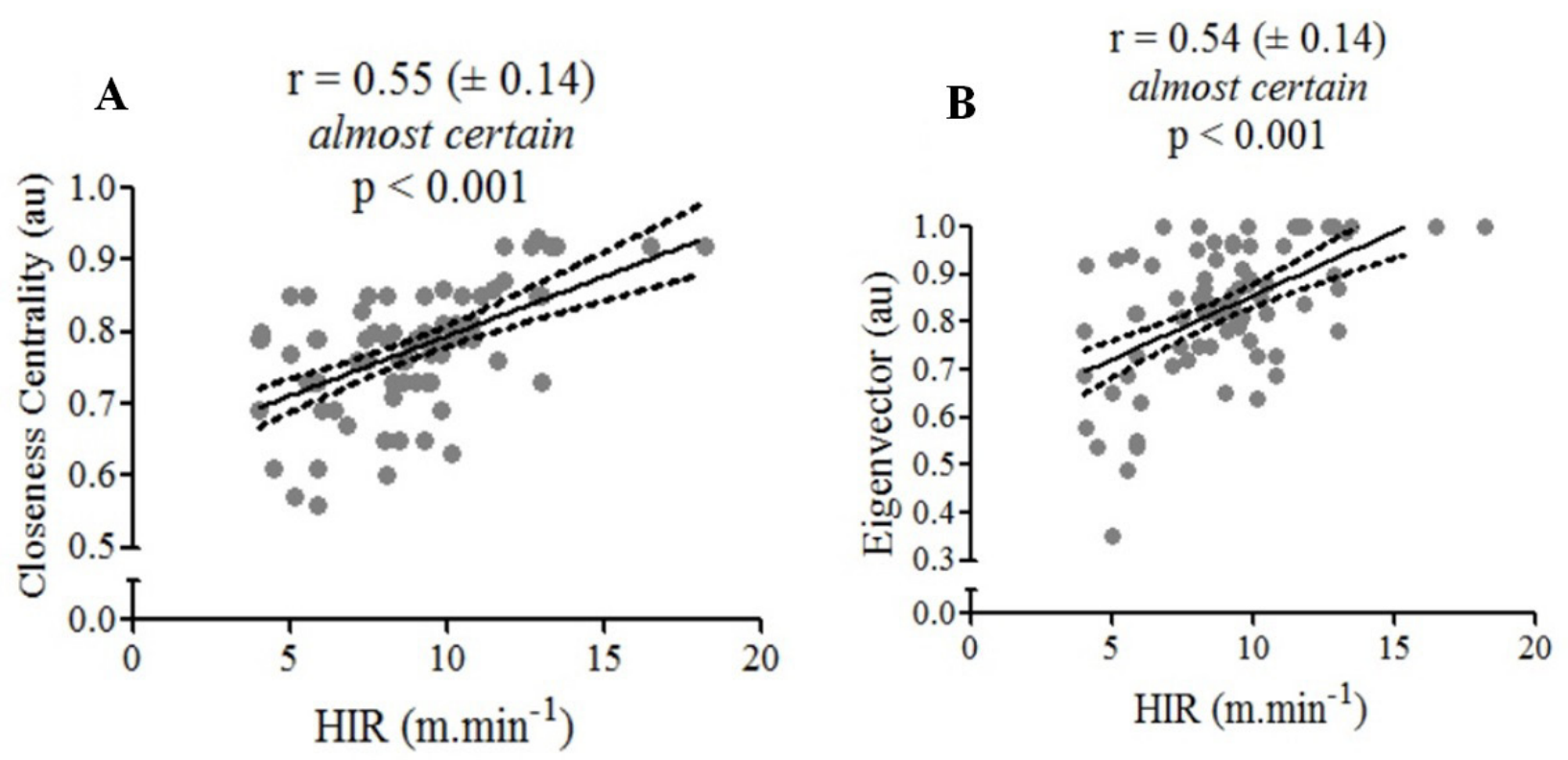

Figure 2. Magnitude of correlation ( $\pm 90 \%$ confidence interval) between distance covered per minute in high-intensity running (HIR) and metrics of social network analysis 
network analysis were not significant $\left(\mathrm{F}_{1,86}: 0.856-\right.$ 2.549; $p$ : 0.11-0.39; $\eta^{2}: 0.01-0.03$ [small]).

Reduced values of IL (sRPE and sRPE-ML) were observed in the forwards compared with the other positions ( $p<0.05$; ES: 0.69-1.48; likely-almost certain). External defenders and external midfielders demonstrated higher values of IL than central defenders and central midfielders ( $p<0.05$; ES: 0.50-0.66; likelyalmost certain). Furthermore, forwards presented lower TD, LIR, HIR, and closeness centrality compared with the other positions ( $p<0.05$; ES: 0.50-1.35; likelyalmost certain). External defenders and external and central midfielders demonstrated higher values of inand out-degree than central defenders and forwards $(p<0.05 ;$ ES: 0.41-0.54; likely). Midfielders (external and central) showed greater eigenvector values than the other positions ( $p<0.05 ; E S$ : $0.38-0.52$; likely) (Table 2). As for correlation analysis, the distance covered per minute in HIR was large, with almost certain association with closeness centrality $(r=0.55)$ and eigenvector values $(r=0.54)$ (Figure 2).

\section{Discussion}

To the best of the authors' knowledge, this is the first study to verify jointly the effects of match location, quality of opposition, match outcome, and playing position on IL, EL, and players' prominence during competitive matches in professional soccer players. The main results were the following: (i) higher values of match IL and HIR were observed in home vs. away matches; (ii) the players presented greater running outputs and betweenness centrality in matches against strong vs. weak opponents; (iii) when the players won the matches, higher running demands and closeness centrality were demonstrated than when they drew or lost; (iv) reduced values of IL, EL, and closeness centrality were noted in the forwards compared with the other positions; (v) the midfielders (external/central) showed greater eigenvector values than the other positions; (vi) the distance covered per minute in HIR was large, with almost certain association with closeness centrality and eigenvector values.

Several studies have demonstrated the influence of situational variables on EL in soccer [6, 16, 30]. However, to the extent of the authors' knowledge, the effects on IL and players' prominence have not been fully investigated. In the present study, IL presented no statistical difference depending on the quality of opposition. In contrast, the study showed greater IL and distance covered in HIR in home vs. away matches. The rationale of these results may be attributed to the external factors involved in home matches, psychological aspects (e.g., greater requirement for a positive outcome), and crowd factors, including differential support from spectators (such as larger/dense/noisy crowds). In recent decades, these components have been studied by researchers across a variety of areas in an attempt to explain the home advantage in athletics [31] and specifically in soccer [32]. Therefore, coaches and practitioners should consider this independent variable when analysing match physical requirements in soccer players.

With regard to the quality of opposition, greater running outputs and number of networks controlled by the players (i.e., betweenness centrality) were observed in matches against strong compared with weak opponents. Previous research showed the same responses as those verified in this study. In the Chinese super league, the top-ranked teams (i.e., strong opponents) presented higher values of sprinting distance and TD without the ball than middle/lower-ranked teams (i.e., intermediary and weak opponents) [33]. Aquino et al. [34] also demonstrated greater locomotor intensity against strong opponents in Brazilian professional soccer players. Furthermore, a previous study implied that against weaker opposition, the team presented better homogeneity of interactions between players and team capacity to play more collectively [6]. Therefore, the present results indicate that professional soccer players should be tactically and physically prepared to cover greater total distances and HIR distances when competing against strong quality opponents [35].

Previous studies have reported the influence of match outcome on running outputs (e.g., HIR distance) in professional soccer players [6, 34]. Match status (i.e., score-line during the match; winning, drawing, losing) is another form of verifying these effects [30]. Taken together, these works show that soccer players perform less high-intensity activities when winning compared with losing [36], i.e., the comfort state of the team when winning may result in a lower distance covered [37]. However, the coaching staff of the reference team analysed in this study provided substantial information on the style of play used during the matches: when winning, the team adopted a counterattacking style, i.e., a direct style (long and fast passes; see Lago [38]); when losing or drawing, the team played with the purpose of controlling the match (maintain ball possession). Therefore, in this study, the counterattacking/transitional styles [39] may result in greater high-intensity activities (e.g., HIR), while the possession style may increase the distance covered in lower 
speed zones. In addition, when the reference team won, the players presented higher values of closeness centrality than when they lost. This demonstrates that players are closer to the teammates in won matches.

In this study, IL, EL, and individual metrics of social network analysis were modulated in accordance with the positional role. In general, external defenders and external midfielders presented greater values of IL and EL compared with central defenders and central midfielders. Also, forwards showed reduced values of IL, EL, and closeness centrality than the other positions. Previous research has shown similar results in different countries, e.g., referring to Brazilian national/ state divisions [6, 7], Italian Serie A League [35], English Premier League [40]. In addition, in this study, the distance covered per minute in HIR was large, with almost certain association with closeness centrality and eigenvector values. Therefore, such outcomes indicate that central and external midfielders (who presented greater eigenvector values) must be physically prepared to cover greater distances in HIR for the organization of the match offensive phases.

This study has 2 limitations that should be recognized. First, the relatively small number of match players observations ( $n=86$ observations) referring to 1 team may compromise the generalization of the results. Second, we used only 1 measure to estimate IL, which could represent an excessive simplification of the psychophysiological construction [41]. However, this study has some novel aspects, namely: (i) a relatively extensive set of independent variables was considered to verify the effects on IL, EL, and interpersonal interactions, i.e., match location, quality of opposition, match outcome, and playing position; (ii) the results can aid sports science and coaching practitioners to prescribe specific training in accordance with situational variables, match outcome, and positional rules (see Practical application).

\section{Practical application}

The data demonstrated the necessity for soccer coaches and practitioners to consider 3 main aspects in the analysis of IL, EL, and interpersonal interactions in professional soccer players: (i) Players should be physically prepared to cover greater running outputs when competing at home or against strong quality opponents. (ii) External defenders and external midfielders exhibit higher IL/EL load during matches compared with the other positions. Therefore, these players should receive a specific strength and conditioning training and recovery strategy. This outcome reinforces the importance of position-specific physical training. (iii) Central and external midfielders must be physically prepared to cover greater distances in HIR for the organization of the match offensive phases.

\section{Conclusions}

Our study demonstrates that load parameters and interpersonal interactions are governed, at least in part, by situational variables, match outcome, and playing position. Specifically, greater values of match IL and HIR were observed in home vs. away matches. The players presented greater running outputs and betweenness centrality in matches against strong vs. weak opponents. When the players won the matches, higher running demands and closeness centrality were noted than when they drew or lost. With reference to playing position, reduced values of IL, EL, and closeness centrality were observed in the forwards compared with the other positions. Midfielders (external/central) showed greater eigenvector values than the other positions. Distance covered per minute in HIR was large, with almost certain association with closeness centrality and eigenvector values.

\section{Acknowledgments}

The authors sincerely thank members of the coaching staff and all players of Botafogo Football Club S/A, Brazil.

\section{Disclosure statement}

No author has any financial interest or received any financial benefit from this research.

\section{Conflict of interest}

The authors state no conflict of interest.

\section{References}

1. Carling C, Reilly T, Williams AM. Performance assessment for field sports. Abingdon: Routledge; 2008.

2. Silva P, Garganta J, Araújo D, Davids K, Aguiar P. Shared knowledge or shared affordances? Insights from an ecological dynamics approach to team coordination in sports. Sports Med. 2013;43(9):765-772; doi: 10.1007/ s40279-013-0070-9.

3. Clemente FM, Martins FML, Couceiro MS, Mendes RS, Figueiredo AJ. Developing a football tactical metric to estimate the sectorial lines: a case study. In: Murgante B, Misra S, Rocha AMAC, Torre C, Rocha JG, Falcão MI, et al. (eds.), Computational science and its applications - ICCSA 2014. Cham: Springer; 2014; 743-753.

4. Grund TU. Network structure and team performance: the case of English Premier League soccer teams. Soc 
Netw. 2012;34(4):682-690; doi: 10.1016/j.socnet.2012. 08.004 .

5. Ribeiro J, Silva P, Duarte R, Davids K, Garganta J. Team sports performance analysed through the lens of social network theory: implications for research and practice. Sports Med. 2017;47(9):1689-1696; doi: 10.1007/ s40279-017-0695-1.

6. Aquino R, Carling C, Palucci Vieira LH, Martins G, Jabor G, Machado J, et al. Influence of situational variables, team formation, and playing position on match running performance and social network analysis in Brazilian professional soccer players. J Strength Cond Res. 2020;34(3):808-817; doi: 10.1519/JSC.0000000 000002725.

7. Barros RML, Misuta MS, Menezes RP, Figueroa PJ, Moura FA, Cunha SA, et al. Analysis of the distances covered by first division Brazilian soccer players obtained with an automatic tracking method. J Sports Sci Med. 2007;6(2):233-242.

8. Impellizzeri FM, Rampinini E, Coutts AJ, Sassi A, Marcora SM. Use of RPE-based training load in soccer. Med Sci Sports Exerc. 2004;36(6):1042-1047; doi: 10.1249/01.mss.0000128199.23901.2f.

9. McLaren SJ, Macpherson TW, Coutts AJ, Hurst C, Spears IR, Weston M. The relationships between internal and external measures of training load and intensity in team sports: a meta-analysis. Sports Med. 2018;48(3): 641-658; doi: 10.1007/s40279-017-0830-z.

10. Wrigley R, Drust B, Stratton G, Scott M, Gregson W. Quantification of the typical weekly in-season training load in elite junior soccer players. J Sports Sci. 2012; 30(15):1573-1580; doi: 10.1080/02640414.2012.709265.

11. Dellal A, Chamari K, Wong DP, Ahmaidi S, Keller D, Barros R, et al. Comparison of physical and technical performance in European soccer match-play: FA Premier League and La Liga. Eur J Sport Sci. 2011;11(1): 51-59; doi: 10.1080/17461391.2010.481334.

12. Weston M, Siegler J, Bahnert A, McBrien J, Lovell R. The application of differential ratings of perceived exertion to Australian Football League matches. J Sci Med Sport. 2015;18(6):704-708; doi: 10.1016/j.jsams.2014. 09.001 .

13. Carling C, Dupont G. Are declines in physical performance associated with a reduction in skill-related performance during professional soccer match-play? JSportsSci.2011;29(1):63-71;doi:10.1080/02640414. 2010.521945.

14. Castellano J, Echeazarra I. Network-based centrality measures and physical demands in football regarding player position: is there a connection? A preliminary study. J Sports Sci. 2019;37(23):2631-2638; doi: 10.1080/ 02640414.2019 .1589919$.

15. Palucci Vieira LH, Carling C, Barbieri FA, Aquino R, Pereira Santiago PR. Match running performance in young soccer players: a systematic review. Sports Med. 2019;49(2):289-318; doi: 10.1007/s40279-018-01048-8.
16. Palucci Vieira LH, Aquino R, Lago-Peñas C, Martins GHM, Puggina EF, Barbieri FA. Running performance in Brazilian professional football players during a congested match schedule. J Strength Cond Res. 2018; 32(2):313-325; doi: 10.1519/JSC.0000000000002342.

17. Borg E, Kaijser L. A comparison between three rating scales for perceived exertion and two different work tests. Scand J Med Sci Sports. 2006;16(1):57-69; doi: 10.1111/ j.1600-0838.2005.00448.x.

18. Fanchini M, Ferraresi I, Modena R, Schena F, Coutts AJ, Impellizzeri FM. Use of the CR100 scale for session rating of perceived exertion in soccer and its interchangeability with the CR10. Int J Sprots Physiol Perform. 2016;11(3):388-392; doi: 10.1123/ijspp.2015-0273.

19. Waldron M, Worsfold P, Twist C, Lamb K. Concurrent validity and test-retest reliability of a global positioning system (GPS) and timing gates to assess sprint performance variables. J Sports Sci. 2011;29(15):1613-1619; doi: 10.1080/02640414.2011.608703.

20. Jennings D, Cormack S, Coutts AJ, Boyd LJ, Aughey RJ. Variability of GPS units for measuring distance in team sport movements. Int J Sports Physiol Perform. 2010; 5(4):565-569; doi: 10.1123/ijspp.5.4.565.

21. Portas MD, Harley JA, Barnes CA, Rush CJ. The validity and reliability of $1-\mathrm{Hz}$ and $5-\mathrm{Hz}$ global positioning systems for linear, multidirectional, and soccer-specific activities. Int J Sports Physiol Perform. 2010;5(4):448458; doi: 10.1123/ijspp.5.4.448.

22. Borgatti SP. Centrality and network flow. Soc Netw. 2005;27(1):55-71; doi: 10.1016/j.socnet.2004.11.008.

23. Freeman LC. Centrality in social networks conceptual clarification. Soc Netw. 1978-1979;1(3):215-239; doi: 10.1016/0378-8733(78)90021-7.

24. Gudmundsson J, Horton M. Spatio-temporal analysis of team sports. ACM Comput Surv. 2017;50(2):22; doi: 10.1145/3054132.

25. Hopkins WG. A scale of magnitudes for effect statistics. New View Stat. 2002;502:411.

26. Wilkinson M, Winter EM. Estimation versus falsification approaches in sport and exercise science. J Sports Sci. 2019;37(1):3-4; doi: 10.1080/02640414.2018.14 79116.

27. De Koning JJ, Noordhof DA. Embrace uncertainty. Int J Sports Physiol Perform. 2019;14(6):697; doi: 10.1123/ ijspp.2019-0419.

28. Hopkins WG, Marshall SW, Batterham AM, Hanin J. Progressive statistics for studies in sports medicine and exercise science. Med Sci Sports Exerc. 2009;41(1):3-13; doi: 10.1249/MSS.0b013e31818cb278.

29. Lacome M, Simpson BM, Cholley Y, Lambert P, Buchheit M. Small-sided games in elite soccer: does one size fit all? Int J Sports Physiol Perform. 2018;13(5):568576; doi: 10.1123/ijspp.2017-0214.

30. Lago-Peñas C. The role of situational variables in analysing physical performance in soccer. J Hum Kinet. 2012;35(1):89-95; doi: 10.2478/v10078-012-0082-9. 


\section{HUMAN MOVEMENT}

L. Gonçalves et al., Match analysis in soccer

31. Jamieson JP. The home field advantage in athletics: a meta-analysis. J Appl Soc Psychol. 2010;40(7):1819_ 1848; doi: 10.1111/j.1559-1816.2010.00641.x.

32. Pollard R, Gómez MA. Components of home advantage in 157 national soccer leagues worldwide. Int J Sport Exerc Psychol. 2014;12(3):218-233; doi: 10.1080/161 2197X.2014.888245.

33. Yang G, Leicht AS, Lago C, Gómez M-Á. Key team physical and technical performance indicators indicative of team quality in the soccer Chinese super league. Res Sports Med. 2018;26(2):158-167; doi: 10.1080/15438 627.2018.1431539.

34. Aquino R, Martins GHM, Palucci Vieira LH, Menezes RP. Influence of match location, quality of opponents, and match status on movement patterns in Brazilian professional football players. J Strength Cond Res. 2017;31(8): 2155-2161; doi: 10.1519/JSC.0000000000001674.

35. Rampinini E, Coutts AJ, Castagna C, Sassi R, Impellizzeri FM. Variation in top level soccer match performance. Int J Sports Med. 2007;28(12):1018-1024; doi: 10.1055/s-2007-965158.

36. Castellano J, Blanco-Villaseñor A, Alvarez D. Contextual variables and time-motion analysis in soccer. Int $\mathrm{J}$ Sports Med.2011;32(6):415-421; doi: 10.1055/s-00311271771.

37. Bloomfield JR, Polman RCJ, O’Donoghue PG. Effects of score-line on team strategies in FA Premier League soccer. J Sports Sci. 2005;23(2):192-193; doi: 10.1080/ 02640410512331334413.

38. Lago C. The influence of match location, quality of opposition, and match status on possession strategies in professional association football. J Sports Sci. 2009; 27(13):1463-1469; doi:10.1080/02640410903131681.

39. Lago-Peñas C, Gómez-Ruano M, Yang G. Styles of play in professional soccer: an approach of the Chinese Soccer Super League. Int J Perform Anal Sport. 2017;17(6): 1073-1084; doi: 10.1080/24748668.2018.1431857.

40. Di Salvo V, Gregson W, Atkinson G, Tordoff P, Drust B. Analysis of high intensity activity in Premier League soccer. Int J Sports Med. 2009;30(3):205-212; doi: 10.1055/s-0028-1105950.

41. Hutchinson JC, Tenenbaum G. Perceived effort - can it be considered gestalt? Psychol Sport Exerc. 2006;7(5): 463-476; 10.1016/j.psychsport.2006.01.007. 